\title{
IX
}

\section{EDUCAÇÃO DE JOVENS E ADULTOS EM MOÇAMBIQUE: UM ESTUDO SOBRE A SITUAÇÃO DE JOVENS E ADULTOS NO CENTRO DE ALFABETIZAÇÃO DE CHIBABAVA*}

Cátia Torres Abu

A Educação de Jovens e Adultos desempenha um papel de grande importância social para seus indivíduos, pois, através dela, deixam de ser vistos como excluídos da sociedade letrada e são incluídos dentro de um novo mundo, da informação e da cultura, do desenvolvimento de novas relações interpes soais, buscando sempre superar uma história de trajetórias escolares anteriores marcadas por idas e vindas fracassadas.

Grande parte destes indivíduos frequentou a escola em outros momentos de suas vidas e, por diferentes razões, foram obrigados a interrompê-los. Sendo assim, a modalidade Educação de Jovens e Adultos em todo o mundo hoje tem a marca acolher um grande número de alunos desistentes dos cursos regulares.

Tal como é o caso de Moçambique: as desistências dos jovens e adultos comprometem os objetivos internacionais assumidos pelo governo moçambicano de "erradicar o analfabetismo" e alcançar uma melhoria de 50\% nos níveis de alfabetização de jovens e adultos, visto que a taxa de analfabetismo da população jovem e adulta apenas tem reduzido entre 1,5\% a 2\% anualmente em todo o país, ao contrário dos $10 \%$ propostos como meta pelo Estado para os próximos anos (MINED, 2011).

Ainda segundo o Ministério de Educação (MINED), os dados indicam altas taxas de evasão. Mais de $1 / 3$ no primeiro trimestre e igual número nos dois últimos trimestres, o que é justificado pelo fraco conhecimento dos métodos de ensino-aprendizagem e motivação dos alfabetizadores; falta de material didático e de leitura; grandes distâncias entre os locais de residência e os centros de alfabetização; horários incompatíveis com as atividades profissionais dos alfabetizandos; casamentos prematuros das mulheres jovens, entre outras.

As questões apresentadas pelo MINED não dão conta da complexidade e dinâmica sociocultural de cada região, e nem cobrem as motivações e traje-

${ }^{*}$ DOI - 10.29388/978-65-86678-41-3-0-f.193-212 
tórias dos alfabetizandos que em situações concretas procuram, permanecem ou não nos programas de alfabetização e educação de jovens e adultos. Assim, esta pesquisa de mestrado defendida em 2016 no Programa de Pós-graduação em Educação da Universidade Federal Fluminense buscou analisar, no âmbito da implementação da política, as razões do acesso e permanência de jovens e adultos no programa de alfabetização regular no Distrito de Chibabava - Moçambique.

Pesquisar sobre as razões que incidem na decisão de jovens e adultos em procurar os centros de alfabetização e permanecer neles, torna-se relevante, pois, mesmo diante de vários entraves escolares, sociais ou econômicas, eles continuam insistindo em retornar à escola. Neste sentido, a proposta desta pesquisa foi analisar como são desenvolvidos os processos de acesso e permanência dos sujeitos do programa de alfabetização regular nesta região.

Para a materialização desta proposta de pesquisa, procurei conhecer as trajetórias escolares dos alunos matriculados no Centro de Alfabetização de Chibabava, tentando compreender as razões implicadas na decisão de procurar a escola, abandonar, retornar/permanecer nela.

Ciente de que toda a pesquisa é resultado de um trabalho estruturado e organizado, portanto, um caminho percorrido, um itinerário, um caminho que trilhamos e com o qual aprendemos muito, não por acaso, mas por não podermos deixar de colocar em xeque "nossas verdades" diante das descobertas reveladas, seja pela leitura de autores consagrados, seja pelos nossos informantes, que têm outras formas de marcar suas presenças no mundo (ZAGO, 2011, p. 307), com o intuito de trazer as nossas "descobertas reveladas", apresento, neste artigo, os caminhos trilhados nessa pesquisa e algumas reflexões vivenciadas no processo.

Tal como Mileto (2009), propomos inverter um ponto de vista mais tradicional nas pesquisas sobre a EJA, nas quais, via de regra, procuram explicações sobre os motivos das desistências (ou evasão), ou seja, procuram respostas sobre por que desistem. Em uma conversão do olhar, pretendemos privilegiar a construção de interpretações e a busca por possíveis respostas sobre porque que, mesmo parecendo tudo tão difícil e tão complicado para muitos, encontramos alfabetizandos que continuam a aprender apesar das dificuldades.

Fruto da dissertação de mestrado, vale ressaltar que este artigo não tem como objetivo defender uma tese sobre o acesso e permanência na Educação de Jovens e Adultos em Moçambique, mas apenas trazer para o debate algumas 
questões preliminares para a compreensão da implementação da política no país visto que ainda são escassos os debates nesta direção.

\section{Moçambique: história e política}

A República de Moçambique está localizada na faixa sul oriental do continente Africano. Faz fronteira com a Tanzânia, ao Norte, e com o Malawi, Zâmbia, Zimbabwe e África do Sul, na parte sudeste. O Leste é banhado pelo Oceano Índico, em uma extensão de linha de costa de 2.515 quilômetros.

A população moçambicana, em 2013, era estimada em 24.366 .112 milhões de habitantes, sendo 11.751 .849 (48,2\%) homens e $12.614 .263(51,8 \%)$ mulheres.

A maior parte da população vive nas zonas rurais $(68,2 \%)$, distante das principais vias de comunicação; $52,1 \%$ são mulheres e $47,9 \%$ homens. A densidade demográfica é de $26 \mathrm{hab} . / \mathrm{km}^{2}$. A taxa de crescimento natural da população é de $2,4 \%$ e de fecundidade é de 5,2 filhos por mulher em idade fértil. A idade mediana da população é de 18 anos.

Quanto a esperança de vida, houve até certo ponto uma evolução, principalmente na população feminina. Os dados dos últimos dois censos e as projeções indicam que em 1997, a idade média de vida dos moçambicanos era de 42 anos (44 para as mulheres e 41 para os homens). Em 2007, passou para 51 anos (53 para as mulheres e 49 para os homens). Já em 2012, para 53 anos (55 para as mulheres e 51 para os homens). Quanto a taxa de mortalidade infantil, é de 99,2 por 1000 nascimentos (INE, 2013).

A população de Moçambique é muito jovem, $45 \%$ da população tem menos de 15 anos de idade. Quase dois em cada três moçambicanos (65\%) tem menos de 25 anos de idade. Esta estrutura etária jovem permite oportunidades de crescimento econômico, mas também coloca grande carga sobre os recursos do país, principalmente nas áreas de saúde e educação.

Em termos de desenvolvimento socioeconômico, tem se registrado avanços significativos, impulsionados pela estabilidade macroeconômica e o crescimento acelerado da economia, que se traduziu em crescimento médio anual na ordem dos 7,6\% do PIB e um rendimento per capita de 5\% no período 2005-2009 (MOÇAMBIQUE, 2011, p. 7).

Os indicadores de desenvolvimento humano sobre o acesso à educação (tanto a nível primário como secundário), assim como o acesso aos serviços básicos de saúde, particularmente nas áreas rurais, apresentou aumentos consi- 
deráveis, inclusive na posse de bens duráveis pelas famílias e melhoria na qualidade de habitação. Em linhas gerais, atestam as tendências positivas importantes do desenvolvimento a longo prazo.

Não obstante ao progresso assinalado pelo poder público, no geral, as disparidades entre zonas ainda são notórias. As pessoas moradoras das zonas urbanas têm maior acesso a serviços sociais básicos comparativamente com a população vivendo nas zonas rurais, justificada muitas vezes pela fraca densidade populacional.

O Estado moçambicano começou a ser criado ainda no momento da luta armada de libertação nacional até 1990, quando a nova Constituição funda o atual Estado de direito democrático. Este processo vem sendo construído desde que Moçambique se viu livre do domínio colonial português, quando o governo entrou em um processo de reestruturação geral do país em todos os seus aspectos. Desde a independência, o país passou por dois tipos/formas de Estado nomeadamente, o socialista de orientação marxista-leninista e o liberal/ democrático.

O país teve o desafio de criar um Estado diferente do anterior que tinha como objetivo a exploração do povo moçambicano, a descriminação assim como a privação de direitos sociais básicos. O Estado Novo tinha como papel principal a criação do Homem Novo $^{3}$ e da Nação Nova.

Moçambique foi declarado uma República Popular através da sua primeira Constituição da República (1975) com uma carga muito grande do Movimento de Libertação; uma preocupação de fazer constar o engajamento na luta contra o colonialismo, o imperialismo, exploração do homem pelo homem.

A partir dos anos 1990, com a aprovação da nova Constituição, que se verifica a queda do socialismo como ideologia de Estado, com consideráveis consequências em Moçambique. Em primeiro lugar, sobretudo depois do acordo de paz, sobrepuseram-se às discussões sobre unidade nacional os debates sobre o caráter multiétnico do país e suas implicações para o futuro do Estado nacional, dos quais tomaram parte tanto pesquisadores estrangeiros como intelectuais moçambicanos.

\footnotetext{
${ }^{3}$ Segundo o Dicionário do pensamento político de Roger Scruton, a expressão "Homem Novo" (ou "novo homem comunista" ou "novo homem socialista") foi usada a partir da década de 1920, tanto por seguidores como por críticos do comunismo soviético, com o intuito de descrever certa transformação não só na ordem econômica, mas também no âmbito da personalidade individual. Segundo a ideologia do Homem Novo, uma vez que o homem possui uma essência histórica, sob uma nova ordem econômica torna-se, em certo sentido, uma criatura diferente, com valores e aspirações integralmente novos (MACAGNO, 2005, p. 9-10).
} 
No artigo $6^{\circ}$ (alíneas "d" e "e") da Constituição aparece pela primeira vez termos muito caros ao liberalismo, ou seja, os direitos humanos, igualdade dos cidadãos perante a lei, democracia e liberdade individual, deixando de forma clara a mudança para o neoliberalismo do Estado moçambicano. Outro conceito novo é introduzido na Constituição de 1990, o "pluralismo político" como manifestação democrática.

A nossa leitura sobre a Constituição de 1990 e a sua atualização em 2004 deixa mais claro o princípio da "queda do muro", o fim de um caminho, de uma utopia, de uma sociedade justa socialista para a construção do capitalismo (TAIMO, 2010).

Nas palavras do Ferrão (2002), neste novo modelo de Estado este e o governo se confundem. O Estado é o conjunto de toda máquina administrativa e seu papel tem muitas vezes se confundido com governo, caracterizando-se como um desafio a distinção entre Estado e governo, pois governo é apenas o executivo.

Acreditamos que se houver a distinção entre estas duas instâncias cruciais para o país, caminharemos para a criação de política educativa de Estado e não do governo como tem acontecido desde a sua independência.

\section{Breve história da Educação em Moçambique}

O setor educativo em Moçambique ainda reflete muitos problemas ligados ao período colonial, período de luta armada de libertação nacional, o período pós-independência, além dos 16 anos de conflito armado e também de algumas políticas socioeconômicas implementadas ao longo das últimas décadas. Tomemos como exemplo deste legado histórico as carências materiais e humanas, as desigualdades regionais no acesso ao sistema educacional, dentre outros.

O período colonial da educação em Moçambique se inicia com o Decreto de 13 de outubro de 1926, de João Belo (Estatuto Orgânico das Missões Católicas Portuguesas da África e Timor), que extinguiu as "missões laicas" ou "missões civilizadoras" e revigorou a intervenção das missões católicas. Neste período, o Estado tinha uma estreita ligação com a Igreja (MAZULA, 1995, p. 78).

Este estatuto tornou ainda mais difícil o direito à educação da população nativa, visto que grande maioria dos africanos habitantes da colônia portuguesa não tinha acesso à educação básica e muito menos a secundária, pois estavam impedidos de se matricular em escolas reservadas para brancos e assimila- 
$\operatorname{dos}^{4}$, visto que o sistema educativo estava organizado de forma discriminatória, em dois sistemas de ensino distintos.

A política colonial no setor da educação visava, essencialmente, manter as diferenças construídas pela metrópole entre os diferentes grupos que viviam na colônia, limitando o acesso à educação a determinados grupos, por meio dos conteúdos ensinados nas escolas, inculcando-lhes os valores metropolitanos.

O objetivo do governo colonial português era de criar um sistema capaz de habilitar o "indígena" para o seu papel especifico de trabalhador "braçal e barato" na economia colonial moçambicana. Por outro lado, o ensino para os brancos, que ocupavam os melhores postos de trabalho, tinha que oferecer uma formação mais completa, que os "indígenas" não precisavam (UEM, 1993).

A reação decisiva contra o regime colonial português em Moçambique deu-se quando três movimentos nacionalistas, a União Democrática Nacional de Moçambique (UDENAMO), Mozambique African National Union (MANU) e a União Africana de Moçambique Independente (UNAMI) sediados na Tanzânia e Zimbabwe, decidiram, em junho de 1962, constituírem-se em uma única Frente de Libertação de Moçambique (FRELIMO). A FRELIMO simbolizava então a união do povo moçambicano e o culminar de um processo de resistências seculares do povo, conduzidos isolada e localmente contra o colonialismo de quinhentos anos (MAZULA, 1995).

As zonas libertadas deixavam de ser espaço restrito a um grupo, a uma categoria social, a uma comunidade etc., para se tornar em um espaço nacional mais aberto, caminhando para relações sociais trans étnicas e intrarraciais. Foi quando pela primeira vez se inaugura um processo de ensino totalmente diferente do regime português da época. A FRELIMO inaugura um ensino voltado para todos, principalmente para as camadas desfavorecidas então excluídas pelo sistema de ensino colonial.

A FRELIMO buscava introduzir em Moçambique, durante este período de luta, um ensino moderno e científico, contrário à violência, à submissão, à marginalização e a favor da libertação dos moçambicanos para sua participação na construção de uma sociedade mais justa e inclusiva.

\footnotetext{
4" Portugal atribuiu à Igreja Católica a tarefa de levar os moçambicanos ao assimilacionismo termo que caracteriza a conversão do moçambicano à cultura portuguesa - adotando a religião católica e a língua portuguesa, afastando-se, a partir de então, de antigos hábitos e costumes característicos de sua cultura. Os moçambicanos assimilados eram considerados por seus compatriotas como traidores de seu povo, pois as mobilizações em defesa do povo moçambicano baseavam-se essencialmente em lealdades ou alianças tribais contra os novos regimes" (VIEIRA, 2006, p. 35).
} 
O objetivo do processo educativo era a formação de um "Homem Novo", inserido na sua realidade cultural e capaz de transformar a vida social em proveito de todos.

A adoção de uma administração centralizada em Moçambique, nos primeiros anos da independência e no setor educativo em particular, entrou em contradição com o processo ascendente de liberalização econômica. O modelo centralista com que o sistema de educação foi montado em Moçambique só seria viável nas condições de uma ótima rede de comunicação e de transportes que pudesse garantir o acesso a todas as regiões. Infelizmente esta realidade não fazia parte de Moçambique, o que provocou uma situação de profunda incapacidade da administração da educação em cumprir suas metas e prazos.

Com a assinatura dos acordos gerais de Paz, em 1992, que deu fim ao conflito armado entre a Renamo e a Frelimo (guerra civil dos 16 anos), surge então a necessidade de reestruturação do sistema de educação de modo a se adequar a este período, assim como as diversas exigências sociais e econômicas.

No início dos anos 1990, vários organismos internacionais como o Programa das Nações Unidas para o Desenvolvimento (PNUD), o Fundo das Nações Unidas para a Infância (UNICEF), o Banco Mundial, entre outros, começaram a exercer grande pressão sobre o governo para que deixasse de priorizar o ensino superior e passasse a concentrar-se no ensino básico, como forma do país participar/cumprir com os objetivos internacionais de oferecer a educação básica para todos, na perspectiva de educação para a satisfação das necessidades básicas de aprendizagem como recomenda a conferência de Jomtien.

Moçambique, signatário do acordo de Jomtien, viu-se obrigado a seguir à letra este plano de ação; em 1992, o governo, com o apoio direto do UNI$\mathrm{CEF}$, concebeu um plano de ensino básico intitulado "Educação Básica: uma estratégia que nasce".

Em cada momento da história de Moçambique, a política de educação foi tomando contornos diferentes. Atualmente tem se verificado uma grande evolução do sistema de ensino no seu todo. O número de alunos no Ensino Primário passou de 3,6 milhões em 2004 para 4,6 milhões em 2007 e 5,3 milhões em 2011. A taxa de escolarização das crianças entre os 6 e os 12 anos é estimada em 93\% (2011) contra 88\% em 2007. Anualmente, um número crescente de alunos conclui a $7^{\mathrm{a}}$ classe. A taxa de conclusão aumentou de $34 \%$, em 2004, para 49\%, em 2010 (MINED, 2012, p. 56).

A cada ano tem se verificado cerca de 300 mil novos ingressos nos diferentes programas de alfabetização de jovens e adultos, dos quais $70 \%$ são do 
sexo feminino. No ensino secundário geral do primeiro ciclo, o número de alunos cresceu de 286 mil em 2004 para 761 mil em 2011. No mesmo ano, o número de alunos no ensino secundário geral do segundo ciclo cresceu mais de quatro vezes, de 45 mil para 191 mil alunos. Nestes dois níveis houve igualmente grandes avanços em termos de equidade de gênero sendo que a percentagem de mulheres passou de 41\%, em 2004, para 47\%, em 2011, no ensino secundário geral do primeiro ciclo e de 39\%, em 2004, para 46\%, em 2011, para o ensino secundário geral do segundo ciclo (MINED, 2012).

O ensino superior tem registrado igualmente grandes avanços em termos de cobertura: as instituições públicas aumentaram em 89\% entre 2004 e 2010 , enquanto que o ensino privado registrou um crescimento de $163 \%$. A rede de instituições do ensino superior cobre, atualmente, todo o país; o número de alunos tem registrado um crescimento entre 2004 e 2010, saltando de 15.113 para 72.636 no ensino público e de 7.143 para 28.726 no ensino privado. Tem crescido também a percentagem de mulheres de 31,6\% em 2004 para 39\% em 2011.

Os dados mostram evolução do sistema educativo quanto ao acesso, mas, encontram-se ainda desafios por ultrapassar, como é o caso da entrada tardia das crianças no ensino primário, em vez dos 6 anos acabam entrando com 7 ou até mesmo 9 anos de idade, assim como a retenção dos jovens e adultos nos vários programas de alfabetização, entre outros (MINED, 2012).

\section{História da alfabetização e educação de adultos em Moçambique}

As primeiras experiências de alfabetização e educação de adultos em Moçambique surgiram durante a luta armada de libertação nacional, fundamentalmente com as ideias de Eduardo Mondlane (Frente de Libertação de Moçambique).

Após a independência, declarou-se a alfabetização e a educação de adultos como sendo campos prioritários para o rápido desenvolvimento do país. Assim, justificam-se os lemas que lideram as campanhas de alfabetização: "aprender para aumentar e melhorar a produção" e "aprender, produzir, lutar". Acreditava-se que, com trabalhadores que soubessem ler e escrever, estar-se-ia em condições de aumentar, automaticamente, a sua produção e tornar-se-iam abertos as causas da revolução (CASTIANO; NGOENHA, 2013, p. 72).

Infelizmente, a alfabetização e escolarização de adultos não foi somente abrilhantada por conquistas. No meio de todos estes avanços, foram surgin- 
do problemas no processo, dentre eles: a falta de programas de pós-alfabetização na base dos quais os adultos poderiam aplicar os conhecimentos apreendidos através da leitura; inexistência de bibliotecas que pudessem estimular a prática da leitura, assim como os poucos incentivos salariais que dificultavam o recrutamento e retenção de alfabetizadores qualificados.

Igualmente, houve uma redução significativa das atividades de alfabetização e educação de adultos devido à intensificação da guerra de desestabilização então movida pelo regime do "apartheid" da África do Sul. Para além da destruição de infraestruturas e perda de vidas humanas, a guerra esteve na origem direta do afluxo de milhares de refugiados moçambicanos nos países vizinhos e de milhões de deslocados em todo o país (MÁRIO; NADJA, 2006, p. 2).

Assim, a alfabetização e escolarização de adultos passaram a estar confinadas às grandes cidades. As únicas exceções foram as iniciativas de organizações não governamentais, religiosas e de indivíduos que mantiveram os programas em pequena escala, tendo produzido, em muitos casos, programas inovadores, como a alfabetização com base em línguas locais.

Com a privatização e liberalização parcial do sistema educativo a partir de 1990, que resultou em profundas transformações em todo o sistema, infelizmente, o setor da alfabetização e educação de adultos foi deixado para trás quando se reconhece o objetivo fundamental do setor, o de garantir o acesso à educação para todos, não devia ser tratado como se fosse um objetivo de longo prazo. A prioridade passou efetivamente para o financiamento do setor básico de ensino, privilegiando-se o ensino de crianças (CASTIANO; NGOENHA, 2013).

Sendo assim, hoje a Educação de Jovens e Adultos é caracterizada como um processo de "redescoberta e resgate" no atual clima de paz e estabilidade social que o país vive desde 1992. Ela é igualmente considerada dentro das políticas públicas como sendo um instrumento indispensável para um desenvolvimento econômico e social sustentável, centrado nos moçambicanos (MÁRIO; NADJA, 2006).

\section{Programas de alfabetização de adultos em Moçambique}

Todos os programas e iniciativas referentes a área de alfabetização de adultos em Moçambique têm como documento orientador para o processo de ensino e aprendizagem o Plano Curricular de Alfabetização e os manuais e ca- 
dernos elaborados pelo MINED através da Direção Nacional de Alfabetização de Adultos (DINAE).

O Plano Curricular de Alfabetização é, na visão do MINED, parte da implementação da Estratégia Nacional de Alfabetização e Educação de Adultos como forma de alcançar o pilar da qualidade e relevância, pela oferta de um currículo voltado para o ensino-aprendizagem da leitura, escrita e cálculo, imanentes na Literacia e Numeracia e, por outro, para o desenvolvimento de habilidades para a vida centradas no saber ser, saber estar e conviver com o diverso (MINED, 2013).

Em Moçambique, são implementados vários programas e iniciativas públicas ou privadas de Alfabetização e Educação de Jovens e Adultos, dentre eles: Programa de Alfabetização Regular (Alfa - Regular), Alfabetização e Literatura (Alfalit), Alfabetização via Rádio (Alfa - Rádio), Programa Família sem Analfabetismo (PROFASA), Distrito Livre do Analfabetismo, Alfabetização em línguas locais entre outros (MINED, 2013).

\section{Análise da Experiência de Alfabetização Regular em Chibabava}

Os sujeitos da Educação de Jovens e Adultos são normalmente pessoas sem acesso ao ambiente escolar e ou insucesso escolar, resultado da própria dinâmica social que os obrigam a não frequentar a escola ou abandoná-la. O retorno à escola nem sempre é fácil, uma vez que, com a idade avançada, muitos desses sujeitos assumem responsabilidades, como a família, o trabalho e os filhos, tendendo a tornar a sua trajetória na EJA muito mais difícil.

A proposta desta pesquisa, como apresentada inicialmente, foi tentar trazer possíveis respostas a algumas questões que vem me incomodando, principalmente sobre as motivações para o acesso e permanência dos sujeitos da Educação de Jovens e Adultos no Programa de Alfabetização Regular em Chibabava.

Mais do que compreender e interpretar os motivos/razões que motivam jovens e adultos a procurar e a permanecer nos centros de alfabetização, pretendo analisar especificamente o que faz os jovens e adultos retornar à escola, mesmo depois de ter interrompido sua trajetória escolar. Chibabava é um Distrito Moçambicano localizado na parte sul da província de Sofala e é habitado pelo povo da etnia Ndau que se localiza, na sua maioria, na região sul do continente africano e, em Moçambique, na região central das províncias de Sofala, Manica e Inhambane. 
A língua falada por este povo é o cindau. O português é usado muita das vezes como uma língua de apoio. Os dados indicam que cerca de $84 \%$ da população maior de 5 anos em Chibabava não sabe falar o português. Os homens são os que mais conhecem a língua $(12 \%)$ em relação às mulheres $(4 \%)$, dada a sua maior inserção na vida social, escolar e no mercado de trabalho.

Apenas $23,76 \%$ da população de Chibabava com mais de 5 anos sabia ler/escrever em 2010. Cerca de 13,14\% das crianças dos 6-13 anos em Chibabava encontravam-se fora da escola. A taxa de analfabetismo para a população de 15 anos e mais se estimava em torno de 70,1\% (INE, 2010).

De acordo com a Estratégia de Alfabetização e Educação de Adultos em Moçambique (2010-2015), o acesso de jovens e adultos de ambos os sexos nos programas de alfabetização e educação de adultos aumentou, segundo os dados do Inquérito do indicador múltiplos, na ordem dos 50\%, permitindo uma redução da taxa de analfabetismo em cerca de $10 \%$, baixando de $60,5 \%$, em 2001, para 50,4\%, em 2007, e para 48,1\%, em 2008.

A Educação de Jovens e Adultos em Chibabava é introduzida logo depois da independência, em 1975, quando a alfabetização é considerada como um dos grandes desafios a nível nacional, dado a elevada taxa de analfabetismo. Foram até o momento, implementados neste distrito quatro programas de alfabetização: Alfabetização Regular, Alfabetização pela Rádio, Alfabetização e Literatura (ALFALIT) e o Programa Família sem Analfabetismo (PROFASA).

Em relação aos alfabetizadores ou educadores para o Programa de Alfabetização Regular em Chibabava, são frequentemente alfabetizadores voluntários ou educadores profissionais. Os alfabetizadores voluntários são normalmente membros das comunidades que se sentem aptos a alfabetizar os outros. Recomenda-se que tenham, no mínimo, o ensino primário completo, isto é a $7^{\mathrm{a}}$ classe do sistema nacional de ensino. Deste grupo, encontramos alfabetizadores voluntários com formação e sem formação. Os alfabetizadores com formação participaram de alguma capacitação e os sem formação são os que nunca a tiveram. Os educadores profissionais são aqueles que tiveram uma formação especializada para lecionar na área de alfabetização de adultos em um Instituto de Formação de Educadores de Adultos (IFEA).

Segundo os dados do mapa do Programa de Alfabetização Regular referente ao ano de 2014, o distrito dispunha de um total de 90 alfabetizadores e educadores profissionais, $61,1 \%$ alfabetizadores, sendo $13,46 \%$ com formação $(14,28 \%$ mulher e $85,71 \%$ homens) e $86,53 \%$ sem formação ( $40 \%$ mulheres e 
$60 \%$ homens). Existiam ainda no mesmo ano, $42,22 \%$ educadores profissionais (36,84\% mulheres e $63,15 \%$ homens).

O Plano Curricular de Alfabetização de adultos apresenta as diretrizes para a elaboração do material didático para o processo de ensino-aprendizagem dos jovens e adultos. Estes materiais podem ser sob a forma de livros ou manuais para alfabetizandos e alfabetizadores/professores constituindo a concretização do currículo ou programa proposto, tanto para o alfabetizador, como para o alfabetizando.

O problema de infraestrutura em Moçambique ainda é um desafio por ultrapassar. Muitas crianças são alfabetizadas sentadas no chão, debaixo de árvores, isto é, ao ar livre. Ás vezes quando tem uma sala, não tem carteira e muito menos um quadro.

Dados disponibilizados pelo MINED, em 2014, o país contava com cerca de 12.353 escolas. Deste número, 29.017 salas de aulas feitas de material convencional (cimento) e as restantes feitas de material local, sendo que 8.461 de tijolos, 9.801 maticadas, 10.493 pau-a-pique e 81.66 de outro material.

Em 2014, o distrito de Chibabava contava com um total de 88 escolas, sendo 141 salas de aulas de material convencional, 9 de tijolos, 93 maticadas, 67 de pau-a-pique e 41 salas de aulas feitas de outro material. 210 (59,82\%) são salas feitas de material local e 40,17\% feitas de material convencional.

Este cenário nacional, assim como de Chibabava, demonstra o desafio que o Estado moçambicano tem para melhorar a infraestrutura das escolas moçambicanas.

Para a infraestrutura do Programa de Alfabetização Regular em Chibabava, segundo os dados do MIMED, funcionaram no período 2013-2014, 146 (44 em 2013 e 102 em 2014) salas de aulas e turmas ao ar livre. Deste número, 49 salas de aulas e 97 turmas ao ar livre, o que demonstra a grande necessidade de investimento em infraestrutura para contribuir com o sucesso da aprendizagem, assim como atrair os alunos para os centros. A vila sede do distrito de Chibabava contava neste mesmo período com um total de 47 (17 em 2013 e 30 em 2014) salas de aulas e turmas ao ar livre. Deste número, 19 salas de aula e 28 turmas ao ar livre.

Durante o nosso trabalho de campo, visitamos 4 centros: dois no coração da vila distrital e outros dois que ficam aproximadamente $2 \mathrm{~km}$ da vila. Nos centros mais distantes, deparamo-nos com uma situação complicada, começando pela inexistência de infraestrutura mínima para que os alunos tivessem um 
pouco de conforto durante as aulas. As aulas ocorrem debaixo de árvores, com quadros feitos de lata e os alunos sentados no chão.

De um total de 45 alunos inscritos em 2015 nos Centros 1 e 2, foi possível aplicar o questionário de perfil a 26 alunos (22 mulheres e 4 homens). A faixa etária varia entre 14-45 anos, sendo 25 alunos na faixa etária de 14-35 (deste, 21 são mulheres e 4 homens); e 1 aluna de 45 anos.

No centro pesquisado, as mulheres representam a maioria, $84,61 \%$, enquanto que os homens representam apenas $15,38 \%$ do total dos alunos submetidos ao questionário.

Quanto a empregabilidade, 2 alunos (um com 22 anos e a outra com 29) têm uma renda mensal. Um é funcionário público (ajudante na área de manutenção de infraestrutura no governo distrital de Chibabava), e a outra é empregada doméstica. Os demais alunos se dedicam a agricultura de subsistência/ cultivo da terra.

Grande parte dos alunos entrou pela primeira vez na escola com idades que variam dos 5-13 (20 alunos - 17 mulheres e 3 homens) os demais entraram na escola pela primeira vez com idades mais avançadas sendo, 5 mulheres e 1 homem.

Quanto ao número de desistências, 19 alunos desistiram uma vez, (16 mulheres e 3 homens), 5 desistiram mais de uma vez (sendo 4 mulheres e 1 homem), e 2 alunas estavam experimentando a escola pela primeira vez.

Os alunos que responderam o questionário apresentaram diferentes justificativas para a decisão de retornar a escola depois de ter deixado quando criança ou até mesmo de iniciá-la pela primeira vez: 16 alunos que responderam ao questionário afirmaram terem sido influenciados a retornar a escola pelos familiares (filho, esposo, mãe, pai, entre outros); 9 por vontade própria e 1 por lideranças comunitárias.

Os resultados do questionário indicam que os adultos consideram a alfabetização e educação de jovens e adultos como sendo um lugar ideal para o aprendizado da língua portuguesa. A maioria dos alunos pesquisados (25) têm a língua portuguesa como a segunda língua, isto é, têm a língua cindau como língua materna ou primeira língua.

As razões do acesso e de permanência apontados pelos sujeitos sofrem influência muito forte de fatores internos e externos. Os fatores internos são os que estão diretamente ligados ao sujeito, como, disposições pessoais, família, e as relações que o sujeito mantém com seus pares, dentro e fora do espaço escolar (comunidade, no grupo de amigos) e os fatores externos estão vinculados 
principalmente aos obstáculos interpostos pelas estruturas socioeconômicas, que se refletem no cotidiano e nas histórias de vida dos alunos (MELLO, 1979, apud, MILETO, 2009).

Apesar da diversidade das histórias de vida dos jovens e adultos do Programa de Alfabetização Regular de Chibabava, apresentaram os mesmos motivos para o retorno à escola, destacando-se, dentre eles, o aprender a ler, escrever e falar a língua portuguesa.

No discurso dos sujeitos entrevistados (alunos, professoras e gestor) foi notória a compreensão da importância da leitura e escrita na atual sociedade contemporânea. $\mathrm{O}$ aprender a ler e escrever é entendido por eles como sendo crucial para a sobrevivência em um mundo em que há uma supervalorização do código escrito.

Mesmo que grande parte dos alunos entrevistados tenha passagem pela escola e por inúmeras encruzilhadas, obrigados a abandoná-la, é notório que hoje estes jovens e adultos sentem necessidade da utilização do instrumento escrita, pelas exigências do mercado de trabalho e não só.

Mesmo que no passado houvesse uma resistência talvez pelo desconhecimento dos benefícios do letramento, hoje, mesmo sem condições mínimas para o decorrer normal das aprendizagens, os alunos continuam frequentando os Centros na busca do código escrito.

A língua portuguesa é uma das razões apontadas como motivadora para que os alunos adiram aos Centros. A língua portuguesa é vista pelos sujeitos como a língua do poder, a língua que permite a inclusão no mundo moderno.

O retorno à escola é por eles visto também como o caminho ideal para garantir um futuro melhor, pois veem a escolarização como sendo a única via para conseguir um emprego formal. Estes alunos projetam seus projetos futuros a partir da escola. Estes projetos são concebidos, segundo Velho (2003), dentro de um campo de possibilidades.

Para além dos aspectos destacados acima, os alunos do programa pesquisado compreendem a instituição escolar como a única capaz de oferecer um conhecimento impossível de ser adquirido no meio familiar, isto é, em casa.

A permanência dos alunos no Centro se justifica em diversas razões, dentre eles no bom relacionamento entre eles, entre as professoras, assim como a ideia do Centro como um espaço criado para eles.

Chama atenção os laços afetivos entre alunos e professoras e entre os próprios alunos, que pode ser na verdade uma condição essencial para a perma- 
nência dos alunos no Centro, pois se sentem envolvidos como atores ativos no processo de ensino e aprendizagem.

Outro aspecto tem a ver com a forma como são tomadas as decisões nos Centros. Para a definição do horário das aulas, por exemplo, as professoras e os alunos afirmam terem negociado conjuntamente. Os alunos dos Centros pesquisados participam do processo de tomada de decisão.

Outro ponto positivo evidenciado foi o fato de os Centros estarem localizados nas proximidades das residências dos alunos, favorecendo a sua permanência.

Outro aspecto não menos importante, mas que certamente contribui significativamente na permanência dos alunos, são as visitas feitas pelas professoras à casa dos alunos, principalmente para o caso de alunos faltosos. Esta é uma estratégia recomendada aos professores de alfabetização do distrito.

Estas visitas são consideradas pelos alunos como sendo encorajadoras, principalmente para alunos com tendência a desistir/faltosos. A presença dos colegas e da professora nas suas casas é de extrema importância, mostra um determinado status de pertencimento de um grupo, o Centro.

Os alunos afirmaram ainda que, para além das visitas, durante as aulas, as professoras têm conversado sobre a importância da escolarização, a importância de eles saberem organizar suas atividades de modo que não os atrapalhe/impeça de frequentar as aulas.

O retorno e a permanência dos alunos do Programa de Alfabetização Regular de Chibabava marca a superação de todas as situações que no passado contribuíram negativamente para a continuidade da sua aprendizagem.

\section{Considerações Finais}

Analisando a história de Moçambique, percebe-se que o país teve que passar por várias transformações ao longo do tempo, principalmente após o período pós independência. Este fenômeno é característico dos países em vias de desenvolvimento.

O país passou de um processo de descolonização quando se viu livre do sistema colonial português, e transitou para um novo sistema colonial, o neoliberal.

Este sistema obriga que Moçambique se alie as grandes potências e aos organismos mundiais como estratégia de sobrevivência, condição que o deixa refém das políticas e programas neoliberais através de acordos internacionais, 
fazendo com que se sinta obrigado a responder pelas recomendações destes tratados.

Atualmente, mesmo que a universalização do ensino ainda seja um sonho para o país, é fundamental reconhecer alguns avanços. Porém, muito ainda precisa ser feito para que se atinja os ideais de uma educação para todos de qualidade, visto que Moçambique se depara com problemas muito sérios na qualidade do ensino oferecido, uma vez que muitos dos alunos que saem das escolas, após anos de aprendizado, mal sabem ler e escrever.

Para a modalidade Educação de Jovens e Adultos, pode-se afirmar que os avanços foram a "passos de camaleão". Isto é, muito lentos em comparação ao ensino primário e secundário destinado as crianças e jovens. Esta lentidão pode ser justificada pela marginalização que a modalidade se encontra no sistema nacional de ensino em geral e nas políticas e ações do Ministério da Educação.

Como evidenciado ao longo do estudo, embora a Educação de Jovens e Adultos seja considerada como estratégica para o desenvolvimento no país, na prática não é o que se evidencia, principalmente porque se restringe a elevação da escolaridade, ainda não se articulando a formação profissional, por exemplo.

Olhar a Educação de Jovens e Adultos nesta perspectiva é olhar para estes sujeitos como agentes ativos no processo de desenvolvimento econômico do país visto que grande parte desta população está na faixa etária considerada.

Este estudo em particular evidenciou que muitos alunos que hoje estão no Programa de Alfabetização Regular tiveram contato com a escola no passado, quando crianças, mas, por várias razões foram obrigados a interromper sua trajetória escolar.

Os dados das entrevistas demonstram ainda que existe no Programa de Alfabetização Regular uma diversidade de sujeitos com histórias e trajetórias de vida bastante diversificadas que evidencia diversidade de contextos que fize$\mathrm{ram} /$ fazem estes jovens e adultos saírem/retornar à escola, assim como permanecer nela. Assim, torna-se fundamental compreender os sujeitos jovens e adultos na sua diversidade.

Olhar a modalidade na diversidade significa compreender a variedade de questões que envolvem a Educação de Jovens e Adultos em geral e os sujeitos em particular. Significa que, para se pensar nas políticas públicas e práticas para esta modalidade, teremos que considerar a discussão sobre a diversidade.

O tema da diversidade na educação em Moçambique é habitualmente restrita na perspectiva da diversidade cultural, linguística e tradicional. Necessi- 
tando acrescentar a esta discussão reflexões que envolvam os sujeitos como indivíduos com suas subjetividades.

Pensar diversidade na Educação de Jovens e Adultos em Moçambique seria dar voz aos sujeitos (alunos e professores) envolvidos no processo. Esta concepção permite ultrapassar os rótulos e estereótipos sociais construídos em torno desses sujeitos.

Os dados das entrevistas evidenciam que para além da aderência de muitos jovens ao programa, a transição para a vida adulta destes é bastante diversa, o que evidencia a necessidade de estudos mais aprofundados sobre o tratamento que a escola dá a estes jovens que normalmente a procuram como mecanismo de ascensão social e inserção no mercado de trabalho.

As entrevistas da pesquisa apontaram que a educação de jovens e adultos é vista como um lugar de recomeço. Um lugar que possibilita a reativação de sonhos/projetos de vida outrora adormecidos. Mesmo que os projetos de vida não se aproximem, há consenso de que é preciso continuar se escolarizando para que o seu projeto de vida se torne realidade.

O tema do acesso e permanência tem um potencial muito grande em Moçambique, especificamente pelo fato de que as ações do governo estão voltadas em grande parte para o acesso nos diferentes níveis. Percebemos que, compreender as razões do acesso e permanência através dos sujeitos pode indicar possíveis caminhos para a política pública. Que as práticas educativas nesta modalidade sejam revistas de modo a adequá-las aos diversos sujeitos que procuram os Centros de Alfabetização e Educação de Jovens e Adultos em Moçambique.

Acreditamos que a superação dos problemas aqui apresentados, e de vários outros, podem de alguma forma contribuir para o aumento das oportunidades de acesso e permanência de jovens e adultos nos programas.

Pesquisas na área precisam ser feitas para que se possa realizar uma real avaliação e análise do impacto das políticas e programas para esta modalidade de ensino em Moçambique.

Ciente das limitações deste estudo, e sem o intuito de encerrar a discussão, tenho a expectativa que este trabalho possibilite a ampliação da discussão sobre as políticas de Educação de Jovens e Adultos em Moçambique, contribuindo, assim, para o surgimento de estudos futuros sobre a temática. 


\section{Referências}

CASTIANO, J. P. NGOENHA, S. E. A longa marcha duma "Educação para Todos" em Moçambique. 3. ed. Maputo: Imprensa universitária, 2013.

FERRÃO, V. Compreender Moçambique: política, economia e fatos básicos. Maputo: Editora escolar, 2002.

INE. III Recenseamento geral da população e habitação. Maputo: INE, 2007.

INE, 2009.

Relatório final do inquérito de indicadores múltiplos. Maputo:

. III Recenseamento geral da população e habitação 2007: indicadores sóciodemográficos distritais - província de Sofala. Maputo: INE, 2010.

. Projeções anuais da população total, urbana e rural: 2007-2040. Maputo: INE, 2010. p.144

III Recenseamento geral da população e habitação 2007: indicadores sóciodemográficos distritais - província de Sofala. Maputo: INE, 2012.

. Estatísticas do distrito de Chibabava. Maputo: INE, 2012.

Anuário estatístico 2013-Moçambique. Maputo: INE, 2014.

MACAGNO, Lorenzo. "Lendo Marx pela segunda vez": experiência colonial e a construção da nação em Moçambique. IV COLÓQUIO MARK E ENGELS, INSTITUTO DE FILOSOFIA E CIÊNCIAS HUMANAS- UNICAMP, 2005. Campinas, Anais... Campinas 8-11 de novembro de 2005.

MÁRIO, Mouzinho.; NANDJA, Débora. A educação de adultos em Moçambique: desafios da Educação Para Todos. Maputo: Relatório para UNESCO, 2006. p. 145

MAZULA, B. Educação, Cultura e Ideologia em Moçambique: 1975 1985. Lisboa: Edição Afrontamento e Fundo Bibliográfico de Língua Portuguesa. 1995.

MILETO, Luiz Fernando. "No mesmo barco, dando força, um ajuda o outro a não desistir"- estratégias e trajetórias de permanência na EJA. Rio de Janeiro: Dissertação (Mestrado) - Programa de Pós-Graduação em Educação da UFF, 2009, 215p. 
MINED. Plano estratégico da educação e cultura 2006-2010/2011. MINED. Maputo, 2006.

. Estratégia de alfabetização de adultos 2010-2015.MINED Maputo, 2011.

. Regulamento de avaliação de alfabetização e educação de jovens e adultos. MINED. Maputo, 2012.

. Plano estratégico da educação 2012-2016.MINED. Maputo, 2012.

. Programas e orientações metodológicas para literacia e numeracia. MINED. Maputo, 2013.

. Plano curricular de alfabetização e educação de adultos em Moçambique. MINED Maputo, 2013.

. Plano de Ação para a Redução da Pobreza Absoluta (PARPA) 2001- 2005. Elografico Maputo, 2001.

Agenda 2025: visão e estratégia da nação. Maputo. Elografico. Maputo. 2003.

. Constituição da República de Moçambique. Maputo: Imprensa Nacional de Moçambique, 2004.

. Plano de Ação para a Redução da Pobreza 2011-2014. INE.Maputo, 2011.

TAIMO, J. U. Ensino superior em Moçambique: história, política e gestão. 2010.229p . Tese (Doutorado em Educação)- Programa de Pós-Graduação em Educação, Universidade Metodista de Piracicaba, Piracicaba, 2010.

UEM. Departamento de História Faculdade de Letras. Maputo: Imprensa da UEM, 1993.

UNESCO. V Confintea: Declaração de Hamburgo a agenda para o futuro. UNESCO, 1999.

. EDUCAÇÃO: um tesouro a descobrir. Relatório para a Unesco da comissão internacional sobre educação para o século XXI, coordenada por J. Delors. Brasília: UNESCO, 1999

. Educação de Jovens e Adultos nos países de língua portuguesa: novos diálogos para a cooperação sul-sul. Brasília: MEC, 2007. 
. Ensinar e aprender: alcançar a qualidade para todos. Relatório de monitoramento global da Educação para Todos. UNESCO,2014.

VELHO, G. Projeto e Metamorfose: antropologia das sociedades complexas. 3. ed. Rio de Janeiro: Zahar, 2003.

VIEIRA, Marcia Aparecida Lima. Educação de adultos, analfabetismo e pobreza em Moçambique. Tese (Doutorado em Educação) - Programa de Pós-Graduação em Educação da Universidade Metodista de Piracicaba- UNIMEP, São Paulo, 2006.

ZAGO, Nadir; CARVALHO, M. Pinto de; VILELA, Rita A. T. (orgs). A entrevista e seu processo de construção: reflexões com base na experiência prática de pesquisa. In: Itinerários de pesquisa: perspectivas qualitativas em sociologia da educação. Rio de Janeiro: Lamparina, 2011. 